\title{
Comparison of Accuracy of Two Global DEMs, and the Extracted DEM from the Topographic Map of the Tafilah Governorate
}

\author{
Yusra Al-husban \\ Department of Geography, Faculty of Arts, the University of Jordan, Amman, Jordan
}

\begin{abstract}
SRTM DEM (shuttle radar topographic mission digital elevation model) and ASTEMR DEM (advanced space-borne thermal emission and reflection radiometer digital elevation model) are now freely available in two resolutions: $90 \mathrm{~m}$ and $30 \mathrm{~m}$. DEM is a computerized representation of the Earth's relief, and is used in many applications such as hydrology, climatology, geomorphology and ecology. There are some important differences in assessing the accuracy of digital elevation models for specific applications. The purpose of this study is to investigate the errors in digital elevation models obtained globally from DEMs $90 \mathrm{~m}, 30 \mathrm{~m}$ ground resolution, and the extracted DEM from a topographic map by digitized contour lines of 1:50,000 scale in a rugged mountainous region and a heterogeneous landscape, using KS (kernel smoothing) interpolation method. For validation purposes, datasets of 250-GCPs (ground control points) distributed over the study area were used to evaluate and compare the accuracy of the two global Dems and the DEM extracted from TM. The main results showed that the $30 \mathrm{~m}$ resolution global (DEM) is the most accurate one among the three. According to the validation results, SRTM with maximum (+) and minimum (-) error elevation is -10_9. M, with mean deviation of KS is -0.00238667 , and RMS (root-mean-square) error of 0.98 , and currently the most accurate model is $30 \mathrm{~m}$ DEM of the study area with no significant differences compared with DEM $90 \mathrm{~m}$.
\end{abstract}

Key words: DEM, accuracy assessment, GPS (global position system), GCP, topographic map, KS.

\section{Introduction}

DEM (digital elevation model) is a digital file consisting of terrain elevations for ground positions at regularly spaced horizontal intervals [1]. DEM data are an essential tool for many applications such as hydrology, climatology, geomorphology and ecology [2-6]. DEMs can be generated using different methodologies that depend on acquisition procedures and techniques, such as satellite-based techniques, field surveying and topographic maps [7-9]. Two global DEMs with horizontal resolutions of $90 \mathrm{~m}$ and $30 \mathrm{~m}$ were freely downloaded for the study area along with the TM (topographic map) to achieve the study goal. TM is a type of map characterized by large-scale

Corresponding author: Yusra Al-husban, associated professor, research fields: physical geography, GIS \& RS applications. details and quantitative representation of relief, usually using contour lines [10]. It is basic to many earth surface processes and finding applications in geomorphology, hydrology and climatology [11]. In this study two global DEMs, and eight TM plates at scale 1:50,000 covered the study area. They were generated by the RJGC (Royal Jordanian Geographic Centre) and scanned individually at 300 DPI (jpg) format. The aim of this study is the comparison of absolute surface heights accuracies of DEMs from global resource data and the DEMs were extracted from TMs, interpolated and validated to determine the best suitable model in the heterogeneous landscape of the Tafilah governorate.

\section{Study Area}

The Tafilah Governorate is located in the south-west part of Jordan (Fig. 1). It extends from 
$30^{\circ} 40^{\prime}-31^{\circ} \mathrm{N}$ and from $35^{\circ} 20^{\prime}$ E- $36^{\circ} \mathrm{N}$, with a total area of $2,114 \mathrm{~km}^{2}$, the topography of Tafilah has complex landforms. The relief can be divided according to elevation into three main zones: the first is where the elevation is -365 below the mean sea level (b.m.s.l) to $425 \mathrm{~m}$ above the mean sea level (a.m.s.l) in the western part as a part of JRV (Jordan Rift valley) in Wadi Araba, and the flat areas which are together, form $25.9 \%$ of the study area; the second is where the elevation ranges from 425.1-1,014 $\mathrm{m}$ above the mean sea level (a.m.s.l) and forms 67\%, which represents low hills, and the third zone represents the high land with

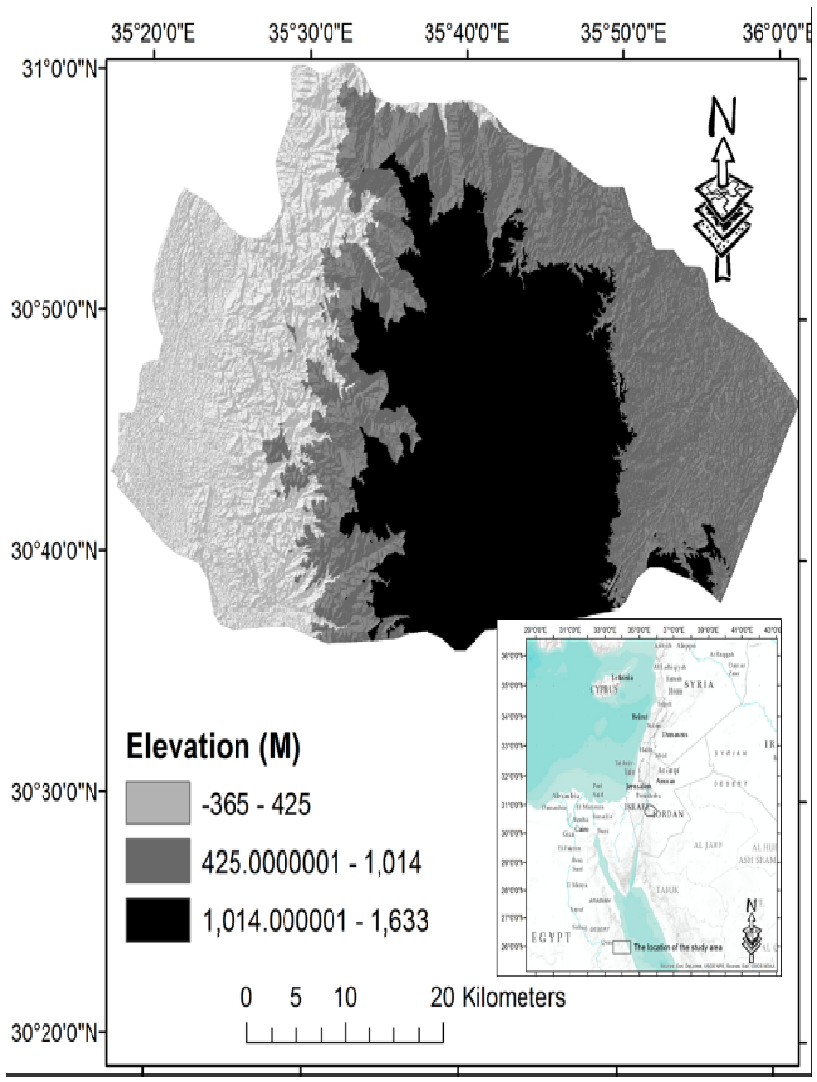

elevation between 1,014.1-1,633 m (a.m.s.l) and forms $16 \%$ of the study area. For the slopes in the study area, nearly $31.7 \%$ of the area is classified as gentle to flat slopes $\left(0-9.8^{\circ}\right)$. While most of areas are high hills, about $48 \%$ are moderately sloping $\left(9-23^{\circ}\right)$, and $20.3 \%$ being steeply sloping $\left(23^{\circ}-69^{\circ}\right)$ (Table 1).

\section{Data and Methodology}

\subsection{GDEMs (Global Digital Elevation Models)}

DEM is a digital file consisting of terrain elevations for ground positions at regularly spaced horizontal

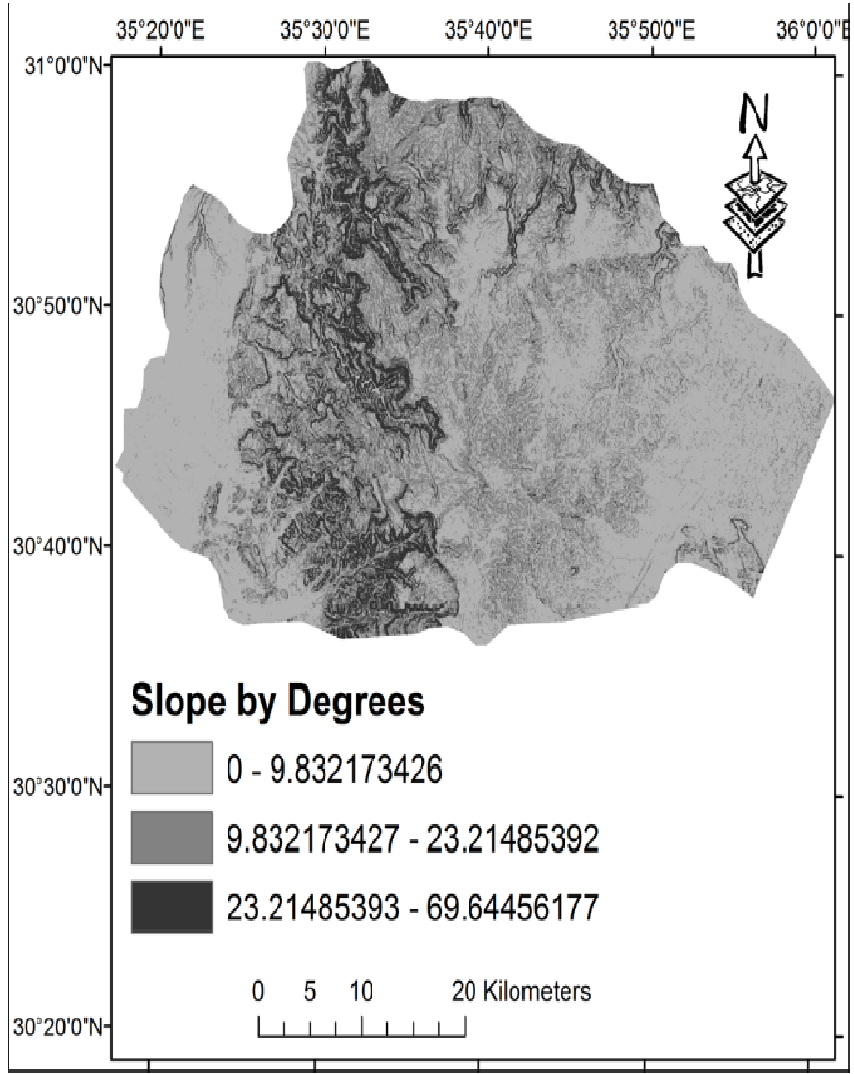

Fig. 1 Elevation (m) and slope (degrees) of the study area from DEM $30 \mathrm{~m}$ and the location of the study site in a base map.

Table 1 Elevation and slope of the study area.

\begin{tabular}{llll}
\hline Elevation classes $(\mathrm{M})$ & Percentage (\%) elevation & Slope classes (degrees) & Percentage (\%) slope \\
\hline$-365-425$ & 25.9 & $0-9.8$ & 11.2 \\
$425.1-1,014$ & 9.7 & $9.9-23$ & 65.5 \\
$1,014.1-1,633$ & 64.4 & $23.1-69.9$ & 23.3 \\
total & 100 & & 100 \\
\hline
\end{tabular}


intervals [1]. In this study, the ASTER (advanced space-borne thermal emission and reflection radiometer) with horizontal resolution of 30 meters was downloaded for Jordan from the website http://asterweb.jpl.nasa.gov/, and the SRTM3 (shuttle radar topographic mission), with horizontal resolution of 90 meters was downloaded freely from the website: https://www2.jpl.nasa.gov/srtm/ster. The ASTER and SRTM3 were rectified and georeferenced to JTM map projection (Zone 36), and WGS84 ellipsoid (Figs. 2 and 3).

\subsection{TMs (Topographic Maps)}

TM is a type of map characterized by large-scale detail and quantitative representation of relief, usually using contour lines in modern mapping, and is a detailed \& accurate graphic representation of cultural \& natural features on the ground [10]. In this study, eight TM plates at scale 1:50,000 generated by the RJGC (Royal Jordanian Geographical Center) covered the study area shown in Fig. 4 and were used to generate DEM by the following steps (Fig. 5).

- Scanning: converting the topographic map into a digital format at 300 DPI jpg format, used to generate the DEM.

- Georeferencing: georeferencing scanned eight topographic plates using known coordinates for the four corners of each map sheet and used these to establish the first 4 control points $[12,13]$. The results of RMSE for each TM plate are shown in Table 2. Then eight topographic sheets covering the Tafilah governorate with contour intervals of $20 \mathrm{~m}$ were rectified and georeferenced to JTM map projection (Zone 36), and WGS84 ellipsoid.

- Mosaicking: the eight topographic plates were merged/mosaicked to have the same cell resolution and coordinate system (Arc Toolbox, Data Management, Raster, and Mosaic).

- Masking: the study area was extracted by mask
(Arc Toolbox, Cartography tools (masking tools), (Fig. 4)). Mosaicking and masking the study area.

- Digitizing: contour lines and elevation points were digitized using ArcGIS software (on-screen digitizing) to convert spatial features (line and points) from a TM into a digital map (Fig. 6).

- Generate and interpolate DEM: the digitized contour lines and the elevation points were used to create the DEM with ground resolution $50 \mathrm{~m}$ by the $\mathrm{KS}$ (kernel smoothing) interpolation method (Fig. 7).

\subsection{GCPs (Ground Control Points)}

A dataset of 250 points taken by GPS (global position system) with known elevations was used to judge and compare the accuracy of the DEMs (Fig. 6).

\subsection{Methodology}

The GIS processing procedures, carried out in this research, consist of several steps: (1) Three available DEMs $90 \mathrm{~m}, 30 \mathrm{~m}$, and the generated DEM $8.9 \mathrm{~m}$ from the topographic map, and the GCGPS dataset was imported within the Arc GIS V.10.4 using spatial analysis tools specifically those of Geostatistical Analyst; (2) To interpolate the three DEMs individually from the Geostatistical Wizard, we applied one of the deterministic methods known as Kernel smoothing interpolation with barriers (ArcGIS Tools/Geostatistical Analyst and Spatial Analyst ARC GIS V.10.2 ); this method gave the best result in smoothing the surface due to the nature of the study area which is characterized by complex and heterogeneous landforms [14]; (3) The obtained interpolated form of each DEM was compared against the known heights of the 250-control points that cover the study area, using Compare-Validation to export age statistical layer (GA) to the points and predict values at unmeasured locations and validate predictions; (4) Finally, statistical analysis was performed to investigate the accomplished results. 

Topographic Map of the Tafilah Governorate

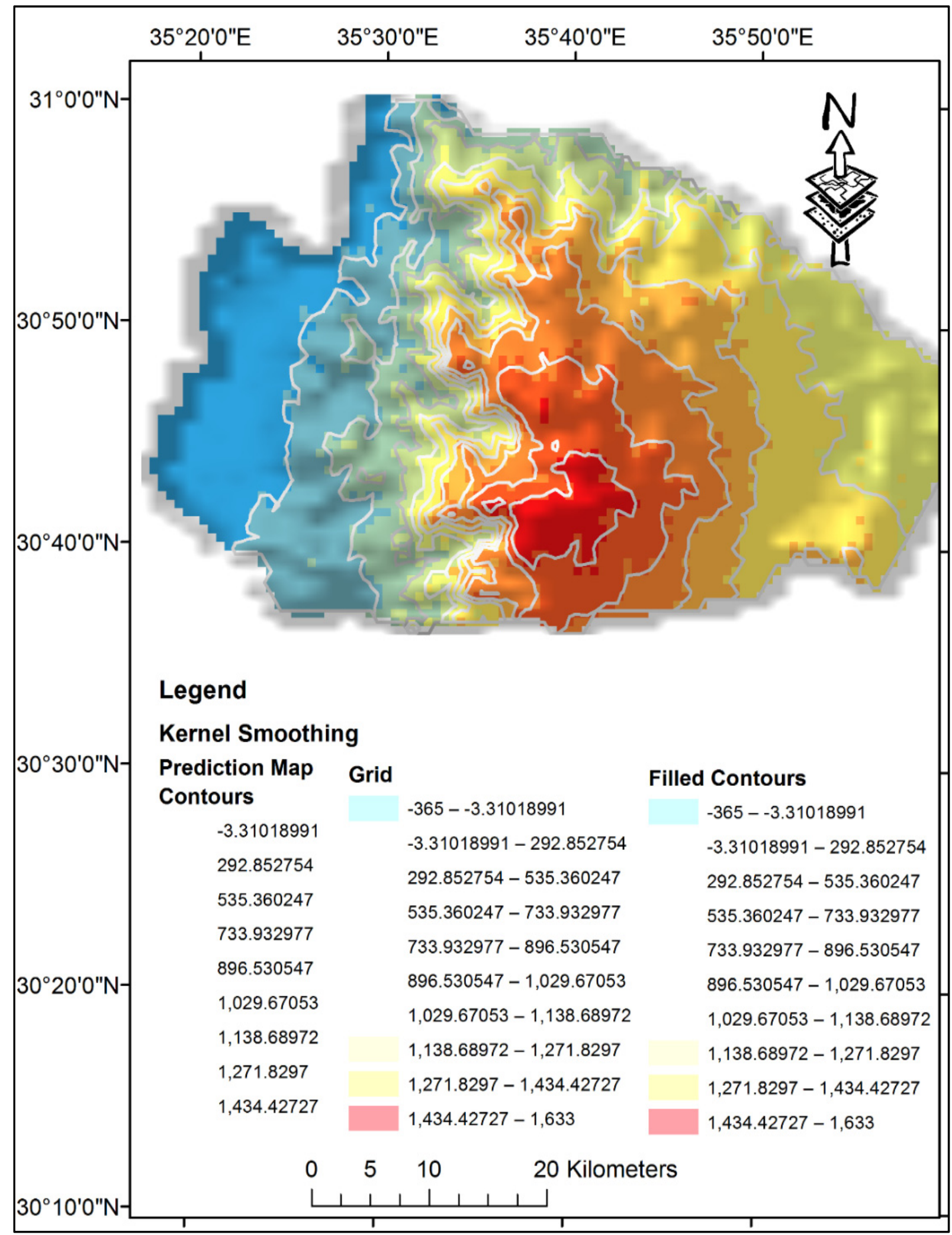

Fig. 2 Kernel smoothing interpolation with barriers, extracted from DEM 30 m. 

Topographic Map of the Tafilah Governorate

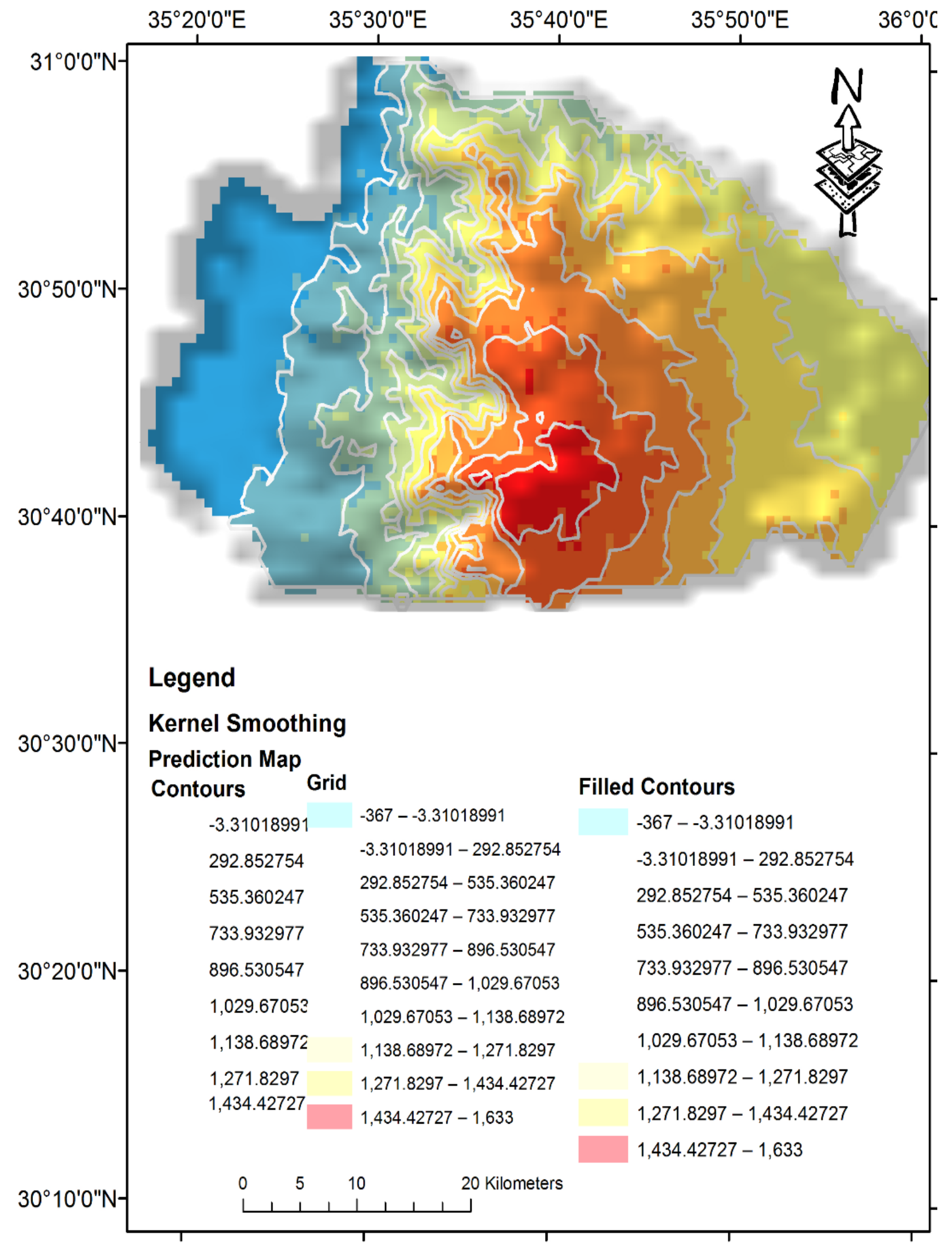

Fig. 3 Kernel smoothing interpolation with barriers, extracted from DEM 90 m. 
Comparison of Accuracy of Two Global DEMs, and the Extracted DEM from the Topographic Map of the Tafilah Governorate

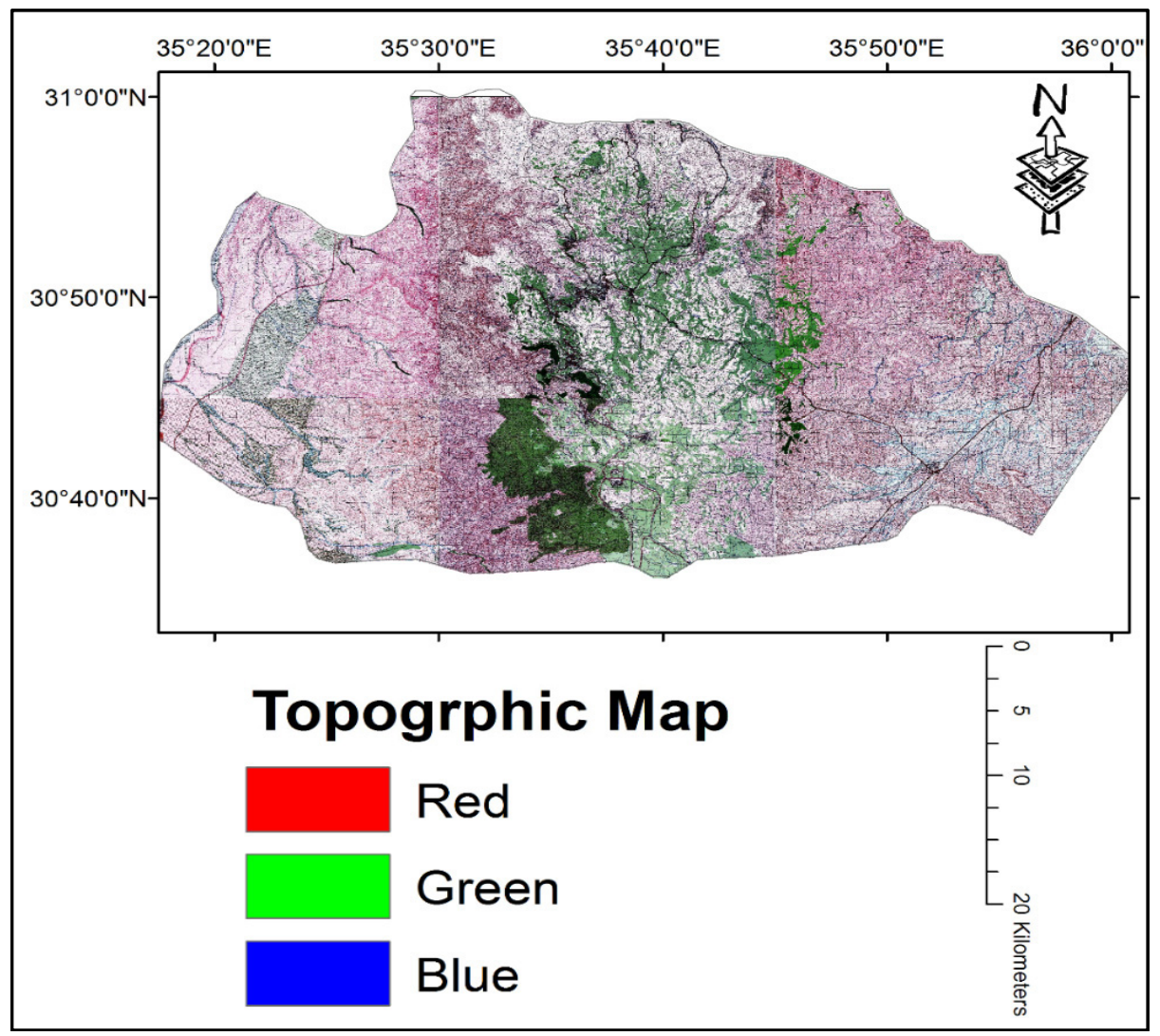

Fig. 4 Mosaicking and masking the eight topographic plates at scale 1:50,000 scanned at 300 DPI (jpg) format.

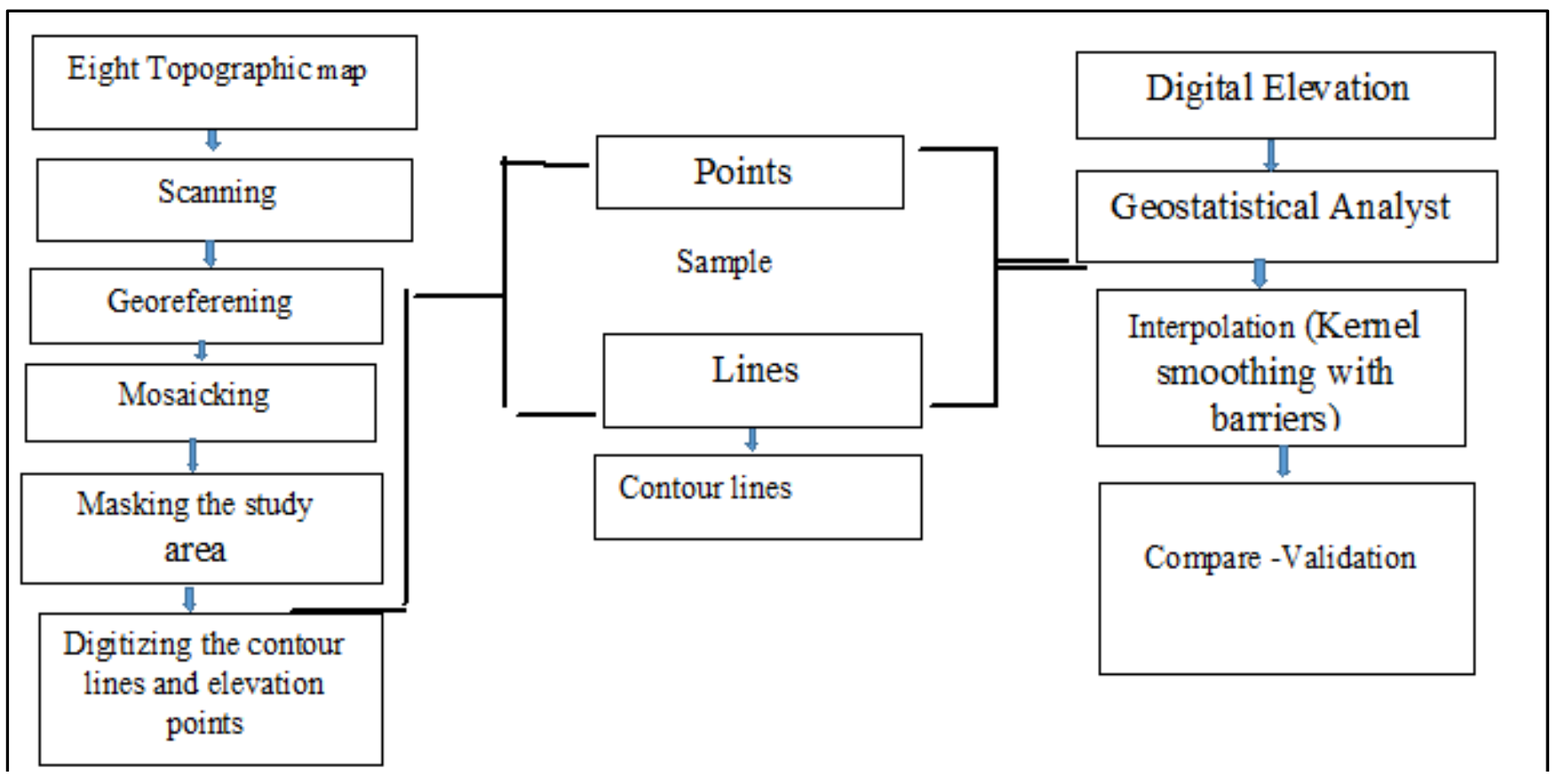

Fig. 5 Flow chart of extracted DEM from TM. 

Topographic Map of the Tafilah Governorate

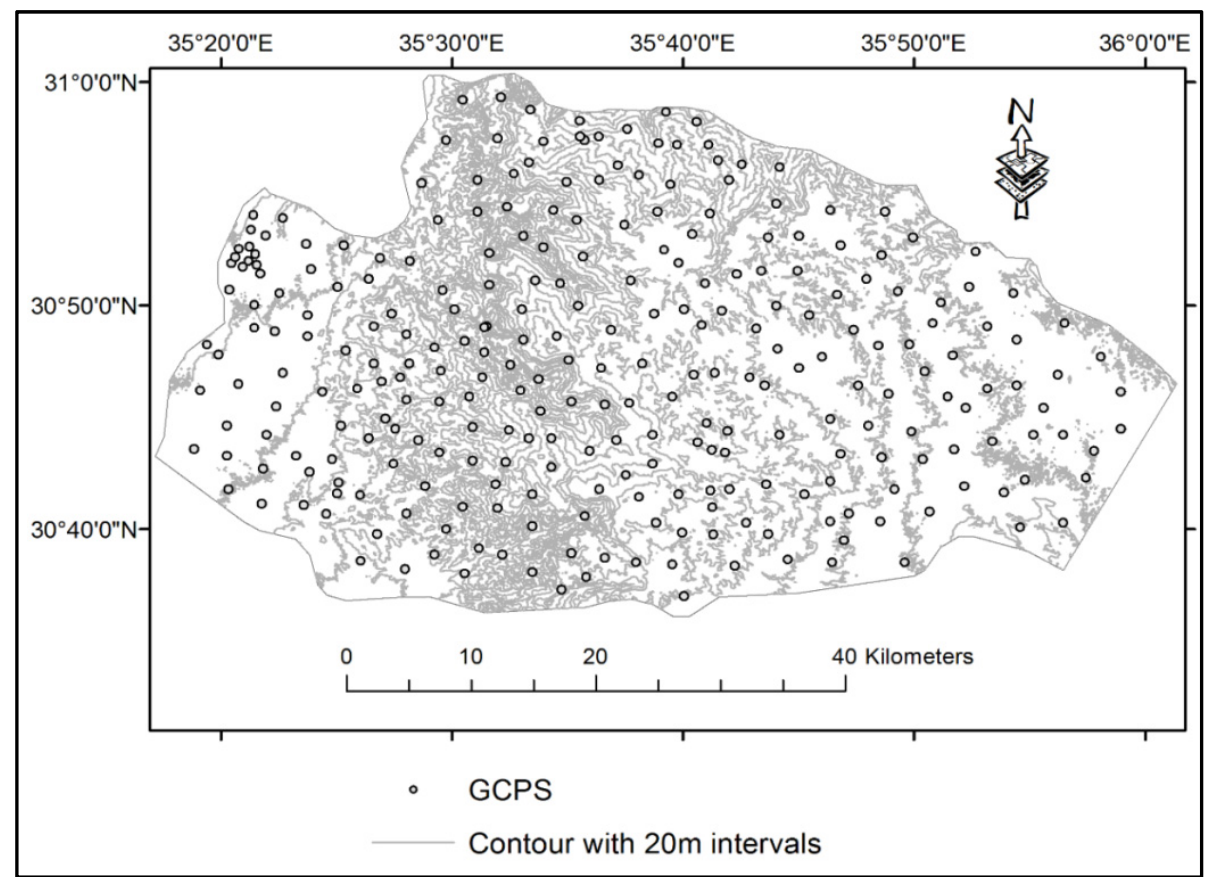

Fig. 6 Contour map with $20 \mathrm{~m}$ intervals and the distribution of GCPs.

Table 2 Total RMS Error for the eight TM plates, covered the study area.

\begin{tabular}{ll}
\hline Topographic plate name & Total RMS error \\
\hline Fifa & 0.000368172 \\
Al_hassa & 0.000268555 \\
Shoubak & 0.000167015 \\
Tafilah & 0.000312000 \\
Wadi Boyija & 0.000334939 \\
Wadi Boyha & 0.000240522 \\
Jrf Adrawish & 0.000313100 \\
Gregrah & 0.000180100 \\
\hline
\end{tabular}

Data Source: Royal Jordanian Geographical Center.

\section{Results, Discussions, and Conclusions}

\subsection{DEM Accuracy}

Globally, the accuracy of DEMs ranges from 7-14 and 6-10 $\mathrm{m}$ for ASTER and SRTM3 respectively, according to USGS (USGS, 2001), and between 10 and 25 according to METI and NASA [15]. For that, the main goal of this paper was to assess the accuracy of the GDEMS within Tafilah governorate, compared to the DEM produced from topographic maps by digitized contour lines of 1:50,000 scale. DEMs accuracy assessment studies have been performed in several regions of the world $[16,17]$. Clearly, it can be noticed from Figs. 2, 3 and 7 that there are some differences between ASTER, SRTM DEMs and the extracted DEM from the TM over the study area. ASTER produces height values ranging from -365 (b.m.s.l) to $1,633 \mathrm{~m}$ (a.m.s.l), while the SRTM's heights' range varies from -367 (b.m.s.l) to $1,633 \mathrm{~m}$ (a.m.s.l), while the heights from the TM DEM range from -302 to $1,613 \mathrm{~m}$. With respect to the evaluation of the accuracy of each DEM independently and compared with reference to GCGPS, the compare/validation of different DEMs was done with the reference to the true elevation data acquired with GPS from Tables 3 and 4. The corresponding heights 
Comparison of Accuracy of Two Global DEMs, and the Extracted DEM from the Topographic Map of the Tafilah Governorate

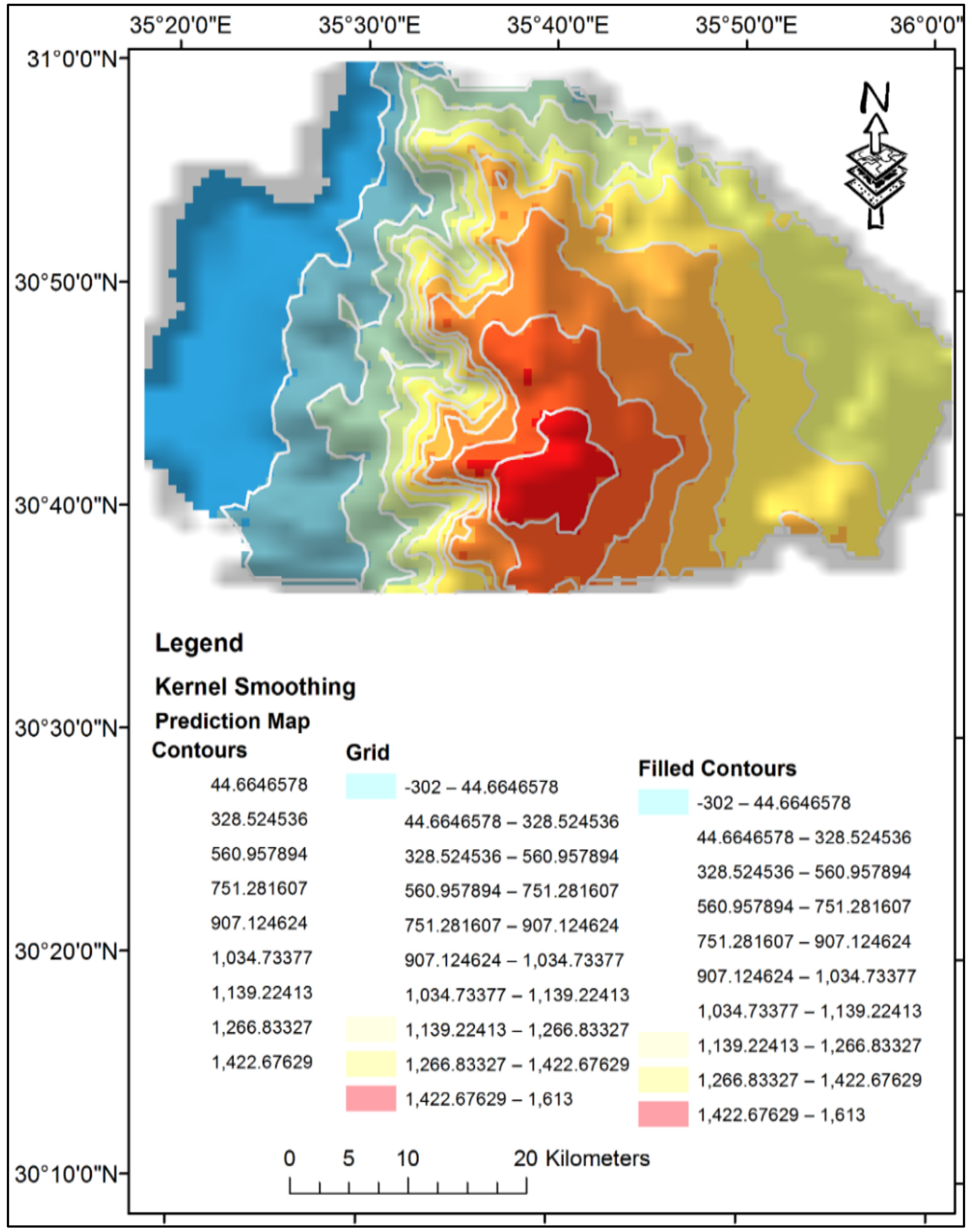

Fig. 7 Kernel smoothing interpolation with barriers from TM. 
from the TM range from -64 to $-20 \mathrm{~m}$, showing that the ASTER DEM yields height differences ranging from $+16 \mathrm{~m}$ to $-15.30 \mathrm{~m}$, with a mean value of $2.59 \mathrm{~m}$ and standard deviation of $8.66 \mathrm{~m}$. On the other hand, the SRTM3 DEM produces height differences varying from $+9 \mathrm{~m}$ to $-10 \mathrm{~m}$, with an average of $-5.20 \mathrm{~m}$ and standard deviation of $5.85 \mathrm{~m}$. Therefore, it can be concluded that the $30 \mathrm{~m}$ resolution ASTER DEM is more accurate than the $90 \mathrm{~m}$ resolution SRTM3 DEM by a factor of about 2.81 .

\subsection{Topographic Contours Data and DEMs Derivation}

The derivation of DEM based on contour lines was extracted from topographic maps with a medium scale of 1:50,000. The contour lines map was established by digitizing on screen. The vertical accuracy of contour lines depends on the scale and ground distance between the contour lines. For that, the vertical RMSE of generating contour lines from the TM can be computed using Eq. (1). Several interpolation methods (Geostatistical analyst) are available in ArcGIS.V10.4 and we found that the best and appropriate DEM interpolation method is Kernel smoothing with barriers, where it fits to the complex physical landscape. Compared to other methods, Kernel smoothing with barriers has been found to adjust themselves to the topographic variations and is more appropriate for geo-morphologically smooth areas [18, 19], with significant topographic variation of the study area Eq. (1).

$$
R M S E=\sqrt{\frac{1}{N}} \sum_{i=1}^{N}\left\{z\left(x_{i}\right)-\hat{z}\left(x_{i}\right\}^{2}\right.
$$

where, $(x i)$ is the predicted value, $z(x i)$ is the observed value, and $N$ is the number of values. The RMSE (root mean square error) expresses the degree to which the interpolated values differ from the measured values, and is based on the assumption that errors are random with a mean of zero and normally distributed around the true value (Table 3 and Fig. 8).

Regarding the available global DEMs, as shown from Table 3, the $30 \mathrm{~m}$ resolution DEM generates the best results with mean value of -0.0003 and RMS is 1.9161 conversely, the $90 \mathrm{~m}$ resolution DEM produces with a mean of -0.0007 and RMS of 2.5329 . Therefore, it can be concluded that there are no significant differences between the accuracies of both global DEMs. Comparing these results against the results obtained from TM DEM shows a mean of 0.3237 and (RMS) 27.1907 showing significant differences between the accuracies of both global DEMs and TM DEM. Thus, the main issue here is that the area and the topographical characteristics of the study area on one hand, and the scale of the topographic map on the other hand are the main factors that determine the level of validation accuracy.

\subsection{Validation/Prediction and Accuracy Assessment}

In this step, we applied the GA (geostatisical analyst) which exports geostatistical layers to points,

Table 3 Comparison of results from DEM $30 \mathrm{~m}, 90 \mathrm{~m}$ and TM, using Kernel smoothing interpolation.

\begin{tabular}{llll}
\hline Statistical analysis & Results from DEM (90) & Results from DEM (30) & Results from TM 50 m \\
\hline Mean & -0.0001 & -0.0002 & 3.237 \\
Root-mean-square & 2.5329 & 1.9161 & 27.1907 \\
Mean standardized & 0.0003 & -9.6001 & 0.0005 \\
Root-mean-square standardized & 1.1214 & 0.98 & 2.0163 \\
Average standard error & 2.6629 & 0.7516 & 26.7083 \\
Regression function & $0.999930063208507 * \mathrm{X}+$ & $0.999922544350119 * \mathrm{X}+$ & $0.994668189261668 * \mathrm{X}+$ \\
\hline
\end{tabular}




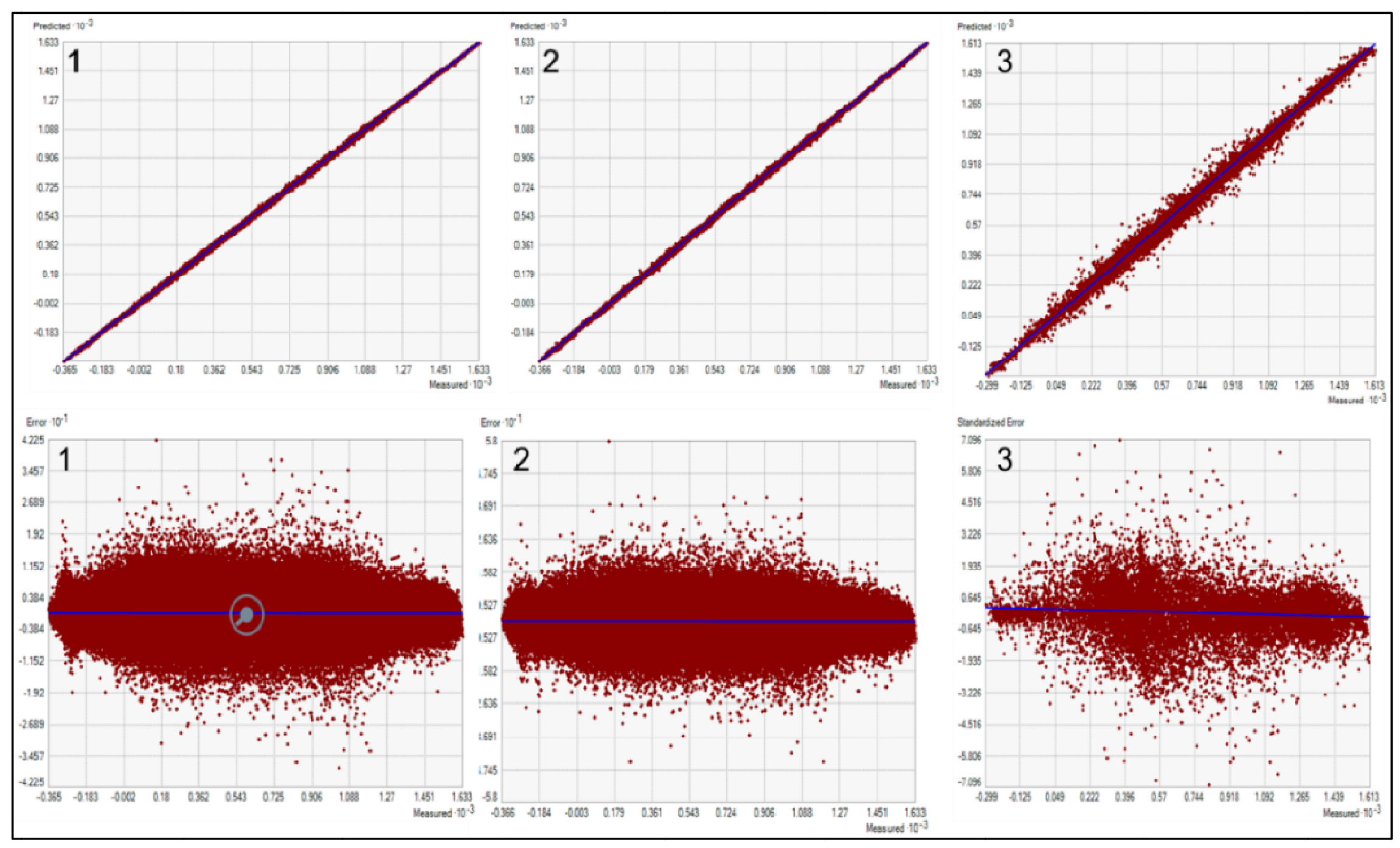

Fig. 8 Results of KS, predicted values against measured values and the error distribution for the different DEMs (1) 90 DEM, (2) 30 DEM and (3) TM DEM. 
Table 4 Statistics of global DEMs' Height differences and the DEM from TM over (GCPS) DEMs are more accurate over of TM DEM.

\begin{tabular}{lllll}
\hline Variables & GCPs & DEM 90 m & DEM 30 m & DEM TM \\
\hline Mimimum $(-\mathrm{m})$ & -365 & -367 & -365 & -302 \\
Maximum $(-\mathrm{m})$ & 1606 & 1606 & 1606 & $1,504.851748$ \\
Mean & 677.2867384 & 671 & 673 & 676.7449149 \\
Max error $(+\mathrm{m})$ & & 16 & 9 & +20 \\
Min error $(-\mathrm{m})$ & & -15 & -10 & -64 \\
\hline
\end{tabular}

predicts values at unmeasured locations, and validates predictions made at measured locations [20]. The different DEMs were validated with reference to elevation data acquired with GPS, which represent the true elevation. The height precision of each DEM should be expressed through the following measurements: root mean square error, (RMSE DEM-j) given by applying Eq. (2).

$$
R M S E D E M-j= \pm \sqrt{\frac{\sum_{i}^{n}=1\left(H_{R e f}-H_{D E M-i}\right)^{2}}{n-1}}
$$

where $\mathrm{H}_{\mathrm{Ref}}$ is the reference DGPS elevation data (true elevation); HDEM-I is the elevation data from each considered source (SRTM, ASTER and topographic contour maps), and $n$ corresponds to the total number of GPS points used for validation. The number of validation GCPs is an important factor in consistency because it conditions the range of stochastic variations on the RMSE and standard deviation values, and the number of ground control points is determined according to the topographical characteristics of the study area in terms of homogeneity or heterogeneity [2]. In this paper, 250 GGCPs have been considered for validation.

\section{Results}

The three considered DEMs (SRTM and ASTER 90 $\mathrm{m}, 30 \mathrm{~m}$, and the DEMs from TM are obtained from different data sources, and their accuracies vary as a function of many source errors. No significant differences are between the results of global DEMS; where their results showed that there are no major differences in the general topographical characteristics, especially in elevation and slope (shown in Table 4). While the results of the digital elevation model derived from the topographical map are so inaccurate that they cannot be relied upon even in theoretical studies; these results are explained by the heterogeneity of the study area, the topographic map scale and the distance between the contour lines. Their visual interpretation shows globally similar characteristics (Fig. 8) which are composed of three distinctive physiographic zones.

\section{Conclusions}

DEMs are the most important factors in geomorphologic and mapping applications. This study investigated the accuracy of two global DEMs, with $90 \mathrm{~m}$ and $30 \mathrm{~m}$ resolutions, along with the DEM extracted from TMs. A 250 represents the truth-value of elevation taken by GPS as a ground control points, used to judge the accuracy of these DEMs. The results showed that the 30 -meter resolution global DEM is the most accurate one among them.

\section{References}

[1] USGS. 2001. "Digital Elevation Models: USGS Digital Elevation Model Information. Rocky Mountain Mapping Center."

http://rmmcweb.cr.usgs.gov/elevation/dpi dem.html Accessed 14 June 2011.

[2] Li, J., and Wong, D. 2010. "Effects of DEM Sources on Hydrologic Applications." Journal of Computers, Environment and Urban Systems 34.

[3] Abrams, M., Hook, S., and Ramachandran, B. 2008. “ASTER User Handbook: Version 2." Jet. Propulsion Laboratory, Pasadena, CA, USA.

[4] Milevski, I. 2005. "Using SRTM3 DEM for Geomorphometrical Analysis." In Stamenkovic, S., ed. Proceedings: Serbia and modern processes in Europe and World (Tara, Serbia, 26-27 May 2005). Faculty of Geography, University of Belgrade, Serbia, (in Serbian). 

Topographic Map of the Tafilah Governorate

[5] Sulebak, J. R. 2000. "Applications of Digital Elevation Models." DYNAMAP. White Paper.

[6] Dowerah, B. 2010. "ASTER DEM Based Studies for Geological Investigation around Singhbhum Shear Zone (SSZ) in Jharkhand, India." Journal of Geographic Information System 2.

[7] Sefercik, U. G. 2007. Comparison of DEM Accuracies Generated by Various Methods.

[8] USGS (U.S. Geological Survey). 1999. "Map Accuracy Standards." USGS Fact, November.

[9] El Bastawesy, M. 2007. "Influence of DEM Source and Resolution on the Hydrographical Simulation of Wadi Keed Catchment, Sinai, Egypt." Egypt Journal of Remote Sensing and Space Sciences 10.

[10] Center for Topographic Information. 2007. "Mapping Information Topo Maps: Frequently Asked Questions."

[11] Ozah, A. P., and Kufoniyi, O. 2008. "Accuracy Assessment of Contour Interpolation from 1:50,000 Topographic maps and SRTM Data for 1:25,000 Topographical Mapping, the International Archives of the Photogrammetry." Remote Sensing and Spatial Information Sciences. Vol. XXXVII. Part B7. Beijing.

[12] ESRI. 2008. "Georeferencing a Raster Dataset." John P. Wilson, John C. Gallant, Terrain Analysis (Principles and Applications). Wiley, 2000.

[13] www.esri.com/geostatisticalanalyst.
[14] Childs, C. 2004. Interpolating Surfaces. ESRI Education Services. www.esri.com/news/arcuser/0704/files/ interpolating.pdf Accessed 14 June 2011.

[15] ASTER GDEM Validation Team. 2009. "ASTER global DEM Validation Summary Report.” METI \& NASA.

[16] Keeratikasikorn, C., and Trisirisatayawong I. 2008 "Reconstruction of $30 \mathrm{~m}$ DEM from $90 \mathrm{~m}$ SRTM DEM with Bicubic Polynomial Interpolation Method." The International Archives of the Photogrammetry, Remote Sensing and Spatial Information Sciences XXXVII. Part B1. Beijing 2008.

[17] Bamler, R. 1999. The SRTM Mission: A Worldwide $30 \mathrm{~m}$ Resolution DEM from SAR, Interferometry in 11 Days. Photogrammetric Week 1999. Heidelberg: Wichmann Verlag.

[18] Mousavi, S., Fallah, A., Abbasnejadc, R., Mousavi, S. R., and Shabani, M. 2007. "The ASTER DEM Generation for Geomorphometric Analysis of Central Alborz Mountains, Iran." Proceedings of the Asian Association of Remote Sensing Conference, Nov. 12-16, Kuala Lumpur, Malaysia.

[19] http://maps.nrcan.gc.ca/topo101/faq_e.php Accessed 11 June 2011.

[20] http://webhelp.esri.com/arcgisdesktop/9.2/index.cfm? TopicName $=$ Georeferencing_a_raster_dataset Accessed 10 June 2011. 